\title{
Erratum: Expanding vocabulary and sight word growth through guided play in a pre-primary classroom
}

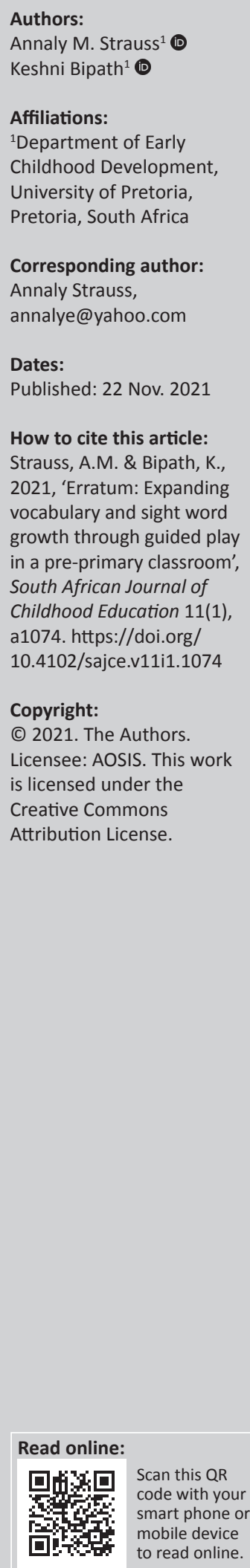

In the version of this article initially published, Strauss, A.M. \& Bipath, K., 2020, 'Expanding vocabulary and sight word growth through guided play in a pre-primary classroom', South African Journal of Childhood Education 10(1), a738. https:/ / doi.org/10.4102/sajce.v10i1.738, the first author's affiliation was given incorrectly in the 'Affiliation' section. The correct affiliation should be 'Department of Early Childhood Development, University of Pretoria, Pretoria, South Africa' instead of 'Faculty of Education, International University of Management, Windhoek, Namibia'.

This correction does not alter the study's findings of significance or overall interpretation of the study's results. The publisher apologises for any inconvenience caused. 